\title{
Condições socioeconômicas e prática de atividades físicas em adultos e idosos: uma revisão sistemática
}

\section{Socioeconomic conditions and practice of physical activity in adults and elderly: systematic review}

Phillipe Augusto Ferreira Rodrigues', Marcelo Paula de Melo', Monique Ribeiro de Assis², Alexandre Palma

\section{Resumo}

Esta revisão sistemática tem como objetivo analisar a relação entre os níveis de prática de atividades físicas e as condições socioeconômicas em adultos e idosos. Foi realizada uma busca na base de dados Pubmed e Scielo até maio de 2015, utilizando as palavras chaves: physical activity, physical exercise, sedentary lifestyle, sedentay behaviour, socioeconomic status e socioeconomic factors e seus respectivos correspondentes na língua portuguesa. Foram adotados os seguintes critérios de inclusão: a) artigos originais que mostravam de forma explícita que investigavam associações de determinantes socioeconômicos com qualquer domínio da atividade física; b) ter amostra composta por adultos e idosos, considerando como idade superior a 18 anos; c) estarem redigidos em língua inglesa ou portuguesa; d) data de publicação a partir do ano 2005. Foram adotados os seguintes critérios de exclusão: a) artigos que tinham como objetivo investigar tais associações, mas envolviam apenas grupos de pessoas com alguma síndrome e/ou doenças, b) estudos de revisão. Foram identificados 573 artigos, deste total foram analisados 43 artigos. Esta revisão identificou que a atividade física está associada aos fatores socioeconômicos, sobretudo a renda, trabalho e escolaridade. De tal modo que os participantes de menor escolaridade, menor renda e/ou pior qualificação profissional estão sujeitos aos maiores níveis de atividade física nos domínios do deslocamento e/ou ocupacional. Por outro lado, o grupo social de maior renda, maior escolaridade e com melhor status profissional estão mais propensos a se engajarem em atividades físicas no lazer.

\section{Palavras-chave}

Atividade física; Fatores socioeconômicos; Inatividade física.

\begin{abstract}
This systematic review aims to analyze the relation between the practice of physical activity levels and social conditions in adults and elderlies people. A search on Pubmed and Scielo database until May 2015 was made using the terms: physical activity, physical exercise, sedentary lifestyle, sedentary behavior, socioeconomic status and socioeconomic factors and yours correspondents in Portuguese language. The following inclusion inclusion criteria were adopted: a) original articles that showed in a clear way that investigate the relation about socioeconomics determinants and the practice of physical activity. b) samples with adults and elderlies with age upper than 18 years old c) written in English or Portuguese language d) publication date since 2005. The exclusion criteria used: a) papers that have with purposes investigate that associations, but involved only a group of people with some disorder or disease; $b$ ) revision studies. In a total of 573 papers, 43 were analyzed. This review identified that physical activity it is associated to socioeconomic factors: income, work and education. Individuals with lower education and income, with poorer professional qualification and / or unemployed are subject to insufficient physical activity $d u$ ring leisure time and in turn to higher occupational overload and displacement. On the other side, the social group that has a great income, a high education and a great professional status are more likely to engaged to do physical activities in leisure.
\end{abstract}

\section{Keywords}

Physical Activity; Socioeconomic Factors; Physical Inactivity.

\section{Introdução}

A prática insuficiente de atividade física tem sido associada à ocorrência de diversas doenças ${ }^{1}$. Diferentes

1 Universidade Federal do Rio de Janeiro. Escola de Educação Física e Desportos, Rio de Janeiro, RJ, Brasil.

2 Universidade do Estado do Rio de Janeiro. Departamento de Programa de PósGraduação em Ciências Do Esporte e do Exercício, Rio de Janeiro, RJ, Brasil. organizações científicas e políticas têm recomendado a quantidade mínima necessária para o tempo de prática de atividade física produzir efeitos positivos sobre a saúde. Entretanto, tem sido observado que não há consenso entre as mesmas ${ }^{2}$. Neste contexto, a prática de atividade física ideal, normatizada dentro 
das recomendações institucionais, perde seu caráter hedonístico e adota características da medicalização, considerando-a como um fenômeno puramente biológico e essencialmente determinante para um estado de saúde ideal ${ }^{3-5}$. Tal discurso desconsidera ou colocam em um plano secundário os processos de relações sociais que poderiam contribuir para reduzir a prática da atividade física ${ }^{6}$.

Frequentemente programas de promoção de atividade física, literalmente, materializam tal prática como um remédio ${ }^{7}$. Tal materialização seria, então, a resposta biopolítica mais eficaz de combate ao sujeito de baixa moral, o sedentário, exercendo, assim, uma forma de controle sanitário, ou, além disto, um controle social ${ }^{8}$.

Durante muito tempo os estudos epidemiológicos buscaram investigar a relação das condições socioeconômicas sobre a prática de atividade física ${ }^{9}$. Estes estudos dedicaram grande parte de sua atenção sobre os fatores individuais, como, por exemplo, escolaridade, renda e profissão $0^{10,11}$. Por outro lado, outros estudos buscaram investigar a associação entre a prática de atividade física e as condições socioeconômicas, a partir de uma perspectiva coletiva, tais como, Índice de Desenvolvimento Humano (IDH), condições adequadas para caminhar no bairro, entre outros ${ }^{12}$. Estas investigações permitem que o foco se desloque do individual para o coletivo, o qual, as relações de atividade física e condições socioeconômicas podem ser analisadas através da perspectiva das políticas públicas ${ }^{12,13}$. Contudo, ainda parecem ser escassas as investigações dessa natureza, que envolvam a prática de atividades físicas, no Brasil.

Este estudo tem o objetivo de realizar uma revisão sistemática na literatura científica, a fim de analisar a associação entre os níveis de prática de atividades físicas e as condições socioeconômicas em adultos e idosos.

\section{Métodos}

Este estudo é uma revisão sistemática da literatura. Foram utilizadas as bases de periódicos Pubmed e Scielo para a seleção de estudos até o mês de maio de 2015. Foram utilizados os seguintes termos: physical activity, physical exercise, sedentary lifestyle, sedentay behaviour, socioeconomic status e socioeconomic factors e seus correspondentes em língua portuguesa: atividade física, exercício físico, estilo de vida sedentário, comportamento sedentário, status socioeconômico e fatores socioeconômicos. Os artigos encontrados tiveram seus títulos e resumos analisados dentro dos seguintes critérios de inclusão: a) artigos originais que mostravam de forma explícita que investigavam associações de determinantes socioeconômicos com qualquer domínio da atividade física; b) ter amostra composta por adultos e idosos, considerando como idade superior a 18 anos; c) estarem redigidos em língua inglesa ou portuguesa; d) data de publicação a partir do ano 2005. Foram adotados os seguintes critérios de exclusão: a) artigos que tinham como objetivo investigar tais associações, mas envolviam apenas grupos de pessoas com alguma síndrome e/ou doenças, entendendo que este podem apresentar necessidades específicas para a prática de atividade física; b) estudos de revisão. As leituras e as seleções dos resumos e posteriormente dos textos na integra foram realizadas por dois autores e inseridas no estudo quando ambos consideravam o estudo apto, quando não havia consenso, os autores discutiam até chegar em um parecer em comum. Foram analisados os objetivos, as amostras, assim como os instrumentos de avaliação da prática de atividade física e os principais resultados.

\section{Resultados}

Foram identificados um total de 573 artigos relacionados aos termos utilizados 
na busca. Após a leitura do título e dos resumos foram selecionados 54 estudos ${ }^{14-65}$ para leitura integral, sendo 11 estudos $^{55-65}$ descartados após a leitura, restando assim $43 \operatorname{artigos~}^{14-55}$ analisados integralmente e inclusos nesta revisão.. Os principais motivos para a exclusão de artigos foi por se tratar de estudos com o objetivo de estabelecer associações entre as condições socioeconômicas com síndromes e/ou doenças, estudos qualitativos e de revisão. O fluxograma do processo de seleção dos artigos ou estudos foi representado na Figura 1.

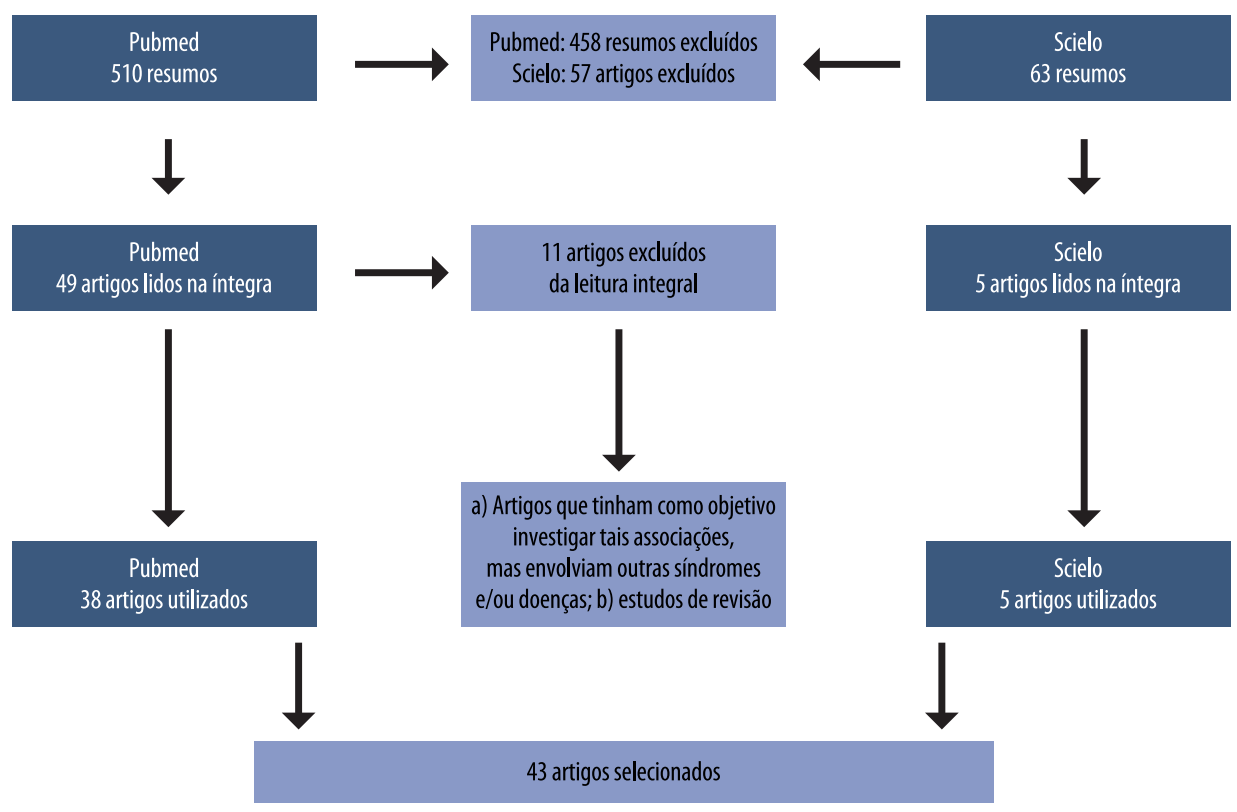

FIGURA 1 - Fluxograma do processo de seleção dos artigos.

Em sua grande maioria, os estudos apresentaram como instrumento de medida da atividade física o Questionário Internacional de Atividade Física (IPAQ), seja na versão curta ${ }^{22,26,29,35,40}$ ou longa ${ }^{11,21,25,31,33,37}$. Os demais utilizaram instrumentos desenvolvidos para os próprios estudos para classificar os participantes de acordo com o nível de atividade física ${ }^{14-17,19,23,27,28,36,38}$. Foram identificados dez estudos com adultos e idosos brasileiros, correspondendo a $23,2 \%$ dos artigos analisa$\operatorname{dos}^{25,29,36-40,47,50}$.

Visto a complexidade e a diversidade das condições socioeconômicas utilizadas pelos estudos analisados, optou-se por debater as variáveis renda, escolaridade e trabalho ${ }^{14-40}$, tendo em vista que têm sido considerados importantes fatores para a prática de atividade física e mais comumente utilizados ${ }^{9,66}$. Dos estudos elegíveis foram extraídos os objetivos, a amostra, os instrumentos utilizados para avaliar a prática de atividade física e os principais resultados (Quadros 1, 2 e 3).

Foram encontrados $21(48,8 \%)$ estudos que analisaram a variável ren$\mathrm{da}^{10,11,15,16,18,20,22,23,25-30,32-35,38-40}$. Todos os estudos analisaram a variável renda de forma categórica, com diferenças sendo observadas para a medida utilizada: renda familiar mensal e anual ${ }^{23,26,28}$ ou renda per capita ${ }^{19}$. Do total de estudos analisados, apenas quatro (19\%) não encontraram associação entre renda e atividade física em qualquer dos seus domínios ${ }^{15,20,26,29}$. Considerando a associação da renda e da atividade física em seus diferentes domínios, foi verificada associação positiva entre renda e atividade física no lazer em oito $(38,1 \%)$ estudos ${ }^{10,16,18,23,23,28,33,35}$ indicando que pessoas com maior renda eram mais propensas a apresentar maiores níveis de atividade física no lazer. Foi observada a associação negativa entre renda 
QUADRO 1 - Características dos estudos que analisaram a associação entre renda e atividade física em adultos e idosos.

\begin{tabular}{|c|c|c|c|c|}
\hline $1^{\circ}$ autor & Objetivo & Amostra/Nação & $\begin{array}{l}\text { Instrumento para medida de } \\
\text { atividade física }\end{array}$ & Resultados \\
\hline $\begin{array}{l}\text { Kahan et } \\
\text { al., }{ }^{9}\end{array}$ & $\begin{array}{l}\text { Avaliar a relação das características } \\
\text { de escolaridade, renda e trabalho, } \\
\text { lazer e esporte com o nível de } \\
\text { atividade física percebida. }\end{array}$ & $\begin{array}{l}445 \text { participantes, sendo } 173 \\
\text { homens e } 211 \text { mulheres. } \\
\text { Idade } 20 \text { a } 65 \text { anos. } \\
\text { Israel. }\end{array}$ & Questionário Baecke. & $\begin{array}{l}\text { A prática esportiva foi } \\
\text { diretamente associada com } \\
\text { a renda. }\end{array}$ \\
\hline $\begin{array}{l}\text { Sávio et } \\
\text { al., }{ }^{39}\end{array}$ & $\begin{array}{l}\text { Analisar os fatores socioeconômicos } \\
\text { e demográficos associados ao nível } \\
\text { de atividade física de trabalhadores. }\end{array}$ & $\begin{array}{l}1.044 \text { trabalhadores de ambos } \\
\text { os sexos vinculados ao Programa } \\
\text { de Alimentação do Trabalhador. } \\
\text { Idade superior há } 18 \text { anos. Brasil. }\end{array}$ & $\begin{array}{l}\text { Recordatório de atividades físicas } \\
\text { da semana anterior, convertido em } \\
\text { taxa metabólica para obtenção do } \\
\text { Nível de Atividade Física. }\end{array}$ & $\begin{array}{l}\text { Renda menor que quatro } \\
\text { salários mínimos foi associada } \\
\text { com o maior nível de atividade } \\
\text { física de trabalhadores. }\end{array}$ \\
\hline $\begin{array}{l}\text { Meyer et } \\
\text { al. }{ }^{27}{ }^{27}\end{array}$ & $\begin{array}{l}\text { Analisar a prevalência de atividade } \\
\text { física em participantes com mais } \\
\text { de } 50 \text { anos baseado no perfil } \\
\text { sociodemográfico e variáveis } \\
\text { ambientais. }\end{array}$ & $\begin{array}{l}8.405 \text { participantes, sendo } 3.542 \\
\text { homens e } 4.863 \text { mulheres. } \\
\text { Maiores de } 50 \text { anos. Residentes } \\
\text { da Suíça. }\end{array}$ & $\begin{array}{l}\text { Instrumento construído } \\
\text { especificamente para o estudo. }\end{array}$ & $\begin{array}{l}\text { Associação inversa entre renda } \\
\text { e atividades habituais. }\end{array}$ \\
\hline $\begin{array}{l}\text { Kaleta e } \\
\text { Jegier., }{ }^{30}\end{array}$ & $\begin{array}{l}\text { Avaliar a associação entre os fatores } \\
\text { socioeconômicos e demográficos } \\
\text { com a atividade física de lazer em } \\
\text { homens e mulheres em idade ativa. }\end{array}$ & $\begin{array}{l}954 \text { participantes, sendo } 454 \\
\text { homens e } 502 \text { mulheres. } \\
\text { Idade de } 25 \text { a } 64 \text { anos. } \\
\text { Polônia. }\end{array}$ & $\begin{array}{l}\text { Questionário Country Wide } \\
\text { Noncomunicable Disease } \\
\text { Intervention Program, World } \\
\text { Health Organization (CINDI, } \\
\text { WHO). }\end{array}$ & $\begin{array}{l}\text { Mulheres de baixa renda } \\
\text { apresentaram maior risco } \\
\text { de inatividade física quando } \\
\text { comparadas às de maior } \\
\text { renda. }\end{array}$ \\
\hline Lee et al., ${ }^{28}$ & $\begin{array}{l}\text { Descrever os padrões de atividade } \\
\text { física e suas interrelações e } \\
\text { associações com os fatores } \\
\text { socioeconômico individuais e estilo } \\
\text { de vida em homens. Shangai. }\end{array}$ & $\begin{array}{l}61.582 \text { participantes. Idade de } 40 \\
\text { a } 74 \text { anos. } \\
\text { China. }\end{array}$ & $\begin{array}{l}\text { Instrumento construído } \\
\text { especificamente para o estudo }\end{array}$ & $\begin{array}{l}\text { O nível da renda foi } \\
\text { positivamente associado } \\
\text { ao exercício e ao trabalho } \\
\text { doméstico, porém } \\
\text { inversamente associado com } \\
\text { o transporte e atividades da } \\
\text { vida diária. }\end{array}$ \\
\hline Trinh et al., & $\begin{array}{l}\text { Identificar o padrão de atividade } \\
\text { física e os fatores associados com } \\
\text { a prática insuficiente de atividade } \\
\text { física. }\end{array}$ & $\begin{array}{l}1.906 \text { participantes. } \\
\text { Idade de } 25 \text { a } 64 \text { anos. } \\
\text { Vietnan. }\end{array}$ & $\begin{array}{l}\text { Questionário Global Physical } \\
\text { Activity Questionnaire (GPAQ). }\end{array}$ & $\begin{array}{l}\text { A inatividade física foi } \\
\text { associada com maior renda } \\
\text { familiar e maior riqueza } \\
\text { familiar apenas nos homens. }\end{array}$ \\
\hline $\begin{array}{l}\text { Zaitune et } \\
\text { al., }{ }^{38}\end{array}$ & $\begin{array}{l}\text { Conhecer a prevalência de } \\
\text { sedentarismo durante o lazer em } \\
\text { idosos do Município de Campinas } \\
\text { analisando-a segundo fatores } \\
\text { demográficos e socioeconômicos, } \\
\text { presença de comorbidades e outros } \\
\text { comportamentos relacionados à saúde. }\end{array}$ & $\begin{array}{l}426 \text { idosos com idade igual ou } \\
\text { superior a } 60 \text { anos. Ambos os } \\
\text { sexos. Brasil. }\end{array}$ & $\begin{array}{l}\text { Instrumento construído } \\
\text { especificamente para o estudo. }\end{array}$ & $\begin{array}{l}\text { Menor renda familiar } \\
\text { per capita apresentou } \\
\text { associação significativa com o } \\
\text { sedentarismo. }\end{array}$ \\
\hline $\begin{array}{l}\text { Kamphuis } \\
\text { et al.,.2. }\end{array}$ & $\begin{array}{l}\text { Examinar a contribuição da } \\
\text { vizinhança, casa e fatores de } \\
\text { desigualdades socioeconômicas na } \\
\text { participação em esportes. }\end{array}$ & $\begin{array}{l}213 \text { bairros. } \\
3.839 \text { participantes. } \\
25 \text { a } 75 \text { anos. } \\
\text { Holanda. }\end{array}$ & $\begin{array}{l}\text { Instrumento construído } \\
\text { especificamente para o estudo. }\end{array}$ & $\begin{array}{l}\text { A chance de não praticar } \\
\text { esporte foi de } 67 \% \text { maior nos } \\
\text { participantes de menor renda. }\end{array}$ \\
\hline $\begin{array}{l}\text { Siqueira et } \\
\text { al. }{ }^{*} 0\end{array}$ & $\begin{array}{l}\text { Descrever a prevalência de } \\
\text { sedentarismo e fatores associados } \\
\text { em populações das áreas de } \\
\text { abrangência de unidades básicas de } \\
\text { saúde em municípios das regiões } \\
\text { Sul e Nordeste do Brasil. }\end{array}$ & $\begin{array}{l}4.060 \text { adultos de ambos os sexos } \\
\text { com idade entre } 30 \text { e } 64 \text { anos e } \\
4.003 \text { idosos de ambos os sexos. } \\
\text { Brasil. }\end{array}$ & IPAQ - Versão curta. & $\begin{array}{l}\text { A baixa renda familiar } \\
\text { apresentou-se como fator de } \\
\text { risco para sedentarismo em } \\
\text { adultos e idosos, sobretudo } \\
\text { em idosos da região Sul do } \\
\text { Brasil. }\end{array}$ \\
\hline Pan et al., ${ }^{22}$ & $\begin{array}{l}\text { a) analisar se os fatores individuais, } \\
\text { apoio social e ambiente físico } \\
\text { apresentam efeitos independentes } \\
\text { na atividade física na população } \\
\text { canadense. } \\
\text { b) Verificar se as influências dessas } \\
\text { variáveis sobre a atividade física } \\
\text { variam de acordo com sexo, idade, } \\
\text { escolaridade e nível de renda } \\
\text { familiar. }\end{array}$ & $\begin{array}{l}5.167 \text { participantes sendo } 2.313 \\
\text { homens e } 2.854 \text { mulheres. } \\
\text { Idade de } 15 \text { a } 79 \text { anos. } \\
\text { Canadá. }\end{array}$ & IPAQ - Versão curta. & $\begin{array}{l}\text { A maior renda familiar } \\
\text { está associada à maior prática } \\
\text { de atividade física. }\end{array}$ \\
\hline $\begin{array}{l}\text { Rovniak et } \\
\text { al. }{ }^{10}{ }^{0}\end{array}$ & $\begin{array}{l}\text { Identificar os padrões de atividade } \\
\text { física em diferentes domínios da } \\
\text { vida. }\end{array}$ & $\begin{array}{l}1.689 \text { participantes ( } 2 \text { bairros } \\
\text { diferentes). Estados Unidos }\end{array}$ & $\begin{array}{l}\text { IPAQ - Versão longa. } \\
\text { Uso de acelerômetro. }\end{array}$ & $\begin{array}{l}\text { O grupo de menor renda } \\
\text { tende a ser mais ativo nas } \\
\text { atividades ocupacionais em } \\
\text { relação aos outros grupos. }\end{array}$ \\
\hline
\end{tabular}


continua

\begin{tabular}{|c|c|c|c|c|}
\hline 10 autor & Objetivo & Amostra/Nação & $\begin{array}{l}\text { Instrumento para medida de } \\
\text { atividade física }\end{array}$ & Resultados \\
\hline $\begin{array}{l}\text { Zanchetta } \\
\text { et al., } 29\end{array}$ & $\begin{array}{l}\text { Analisar as prevalências de } \\
\text { inatividade física global e no lazer, } \\
\text { e a associação desses com fatores } \\
\text { demográficos e socioeconômicos } \\
\text { em adultos. }\end{array}$ & $\begin{array}{l}2.050 \text { participantes, sendo } 1.028 \\
\text { mulheres e } 1.022 \text { homens. } \\
\text { Idade de } 18 \text { e } 59 \text { anos. } \\
\text { Brasil. }\end{array}$ & IPAQ - Versão curta. & $\begin{array}{l}\text { Não foram encontradas } \\
\text { associações entre renda e } \\
\text { atividade física no modelo } \\
\text { estatístico final. }\end{array}$ \\
\hline $\begin{array}{l}\text { Boone- } \\
\text { Heinonen } \\
\text { et al., }\end{array}$ & $\begin{array}{l}\text { Estimar as associações } \\
\text { longitudinais dos determinantes } \\
\text { socioeconômicos e a prática de } \\
\text { atividade física. }\end{array}$ & $\begin{array}{l}5.115 \text { participantes. } \\
\text { Idade de } 18 \text { a } 30 \text { anos. } \\
\text { Acompanhamento de } 15 \text { anos. } \\
\text { Estados Unidos da América. }\end{array}$ & $\begin{array}{l}\text { Instrumento construído } \\
\text { especificamente para o estudo. }\end{array}$ & $\begin{array}{l}\text { Os participantes de } \\
\text { maior renda por bairros } \\
\text { apresentaram maior nível de } \\
\text { atividade física assim como } \\
\text { maior renda por bairro. }\end{array}$ \\
\hline $\begin{array}{l}\text { Bauman et } \\
\text { al. }{ }^{16}\end{array}$ & $\begin{array}{l}\text { Descrever como a atividade } \\
\text { física-trabalho, deslocamento } \\
\text { e de lazer - é distribuida por } \\
\text { idade, escolaridade, renda, área } \\
\text { urbana e rural dentro de cada } \\
\text { país e comparar essas associações } \\
\text { entre diferentes estágios de } \\
\text { desenvolvimento socioeconômico. }\end{array}$ & $\begin{array}{l}\text { Participantes v de lo, entre 18-64 } \\
\text { anos. com idade entre } 18 \text { e } 64 \text { anos. } \\
\text { Austrália } 15.786 \text { (Homens:7.870 / } \\
\text { Mulheres:7.815); } \\
\text { China 142693 (Homens:6.3931 / } \\
\text { Mulheres: } 78.295) \text {; } \\
\text { Fiji } 6.763 \text { (Homens:2.878 / } \\
\text { Mulhere:3.343); } \\
\text { Malásia 2.572 (Homens:1.044 / } \\
\text { Mulheres:1.528); } \\
\text { Nauru 2.085 (Homens:925 / } \\
\text { Mulheres:952); } \\
\text { Filipinas 3.307 (Homens:1.660 / } \\
\text { Mulheres:1.647). }\end{array}$ & $\begin{array}{l}\text { Instrumento construído } \\
\text { especificamente para o estudo } \\
\text { em cada país. }\end{array}$ & $\begin{array}{l}\text { Alta renda aumenta em duas } \\
\text { vezes a chance de praticar } \\
\text { atividade física no lazer. } \\
\text { Alta renda foi inversamente } \\
\text { associada com ser fisicamente } \\
\text { ativo no trabalho e no lazer. } \\
\text { Não houve associações } \\
\text { significativas entre renda e } \\
\text { atividade física nas Filipinas e } \\
\text { na Malásia. }\end{array}$ \\
\hline $\begin{array}{l}\text { Nédó e } \\
\text { Paulik., }\end{array}$ & $\begin{array}{l}\text { Estudar as diferenças } \\
\text { socioeconômicos relacionadas ao } \\
\text { comportamento de saúde e estado } \\
\text { nutricional em cidadãos Húngaros } \\
\text { e Romenos. }\end{array}$ & $\begin{array}{l}1.099 \text { húngaros, sendo } 575 \\
\text { mulheres e } 524 \text { homens. } \\
852 \text { romenos, sendo } 437 \\
\text { mulheres e } 415 \text { homens. } \\
\text { Maiores de } 18 \text { anos. } \\
\text { Hungria e Romênia. }\end{array}$ & $\begin{array}{l}\text { Instrumento construído } \\
\text { especificamente para o estudo. }\end{array}$ & $\begin{array}{l}\text { A prática regular de atividade } \\
\text { física no lazer não foi associada } \\
\text { à renda, em ambos os sexos. }\end{array}$ \\
\hline $\begin{array}{l}\text { Komar- } \\
\text { Samardzija } \\
\text { et al., }{ }^{20}\end{array}$ & $\begin{array}{l}\text { Determinar a relação da frequência } \\
\text { e do gasto calórico da atividade } \\
\text { física com: } \\
\text { 1)Suporte social. } \\
\text { 2)Auto-eficácia. } \\
\text { 3)Imagem corporal } \\
\text { 4)Barreiras } \\
\text { 5) Escolaridade e renda familiar }\end{array}$ & $\begin{array}{l}50 \text { mulheres afro-americanas com } \\
\text { diabetes tipo } 2 . \\
\text { Maiores de } 18 \text { anos. } \\
\text { Estados Unidos da América. }\end{array}$ & $\begin{array}{l}\text { Modifiend CHAMPS Physical } \\
\text { Activity Questionnaire. }\end{array}$ & $\begin{array}{l}\text { A prática regular de atividade } \\
\text { física no lazer não foi associada } \\
\text { à renda. }\end{array}$ \\
\hline Cruz et al., ${ }^{26}$ & $\begin{array}{l}\text { Determinar as associações entre o } \\
\text { nível de atividade física, auto- } \\
\text { percepção do stresse acadêmico } \\
\text { e load e hábitos alimentares em } \\
\text { jovens universitários. }\end{array}$ & $\begin{array}{l}275 \text { participantes, sendo } 89 \\
\text { homens e } 186 \text { mulheres.- } \\
\text { Porto Rico. }\end{array}$ & IPAQ - Versão curta. & $\begin{array}{l}\text { Alta proporção de participantes de } \\
\text { baixa renda nas atividades leves, } \\
\text { enquanto uma alta proporção dos } \\
\text { participantes no mais alto nível } \\
\text { de renda apresentaram níveis } \\
\text { moderados de atividade física, } \\
\text { embora sem significância estatística. }\end{array}$ \\
\hline $\begin{array}{l}\text { Pudrovska e } \\
\text { Aniskin., }{ }^{18}\end{array}$ & $\begin{array}{l}\text { Examinar a associação entre o nível } \\
\text { socioeconômico na vida jovem com } \\
\text { a prática de atividade física até os } \\
65 \text { anos, elucidar os mecanismos e } \\
\text { explorar as diferenças de gênero. }\end{array}$ & $\begin{array}{l}\text { Estudantes de um colégio } \\
\text { americano em } 1.957 \text { (17-18 anos), } \\
\text { em } 1.975 \text { (36 anos), em } 1.993 \\
\text { (53-54 anos) e } 2.004 \text { ( } 64-65 \text { anos). } \\
\text { Analisados } 2.615 \text { homens e } 3.163 \\
\text { mulheres. Estados Unidos da } \\
\text { América. }\end{array}$ & $\begin{array}{l}\text { Em } 2004 \text { - Relatado o número } \\
\text { de horas por mês de atividades } \\
\text { leves e de atividades vigorosas. } \\
\text { Em } 1957 \text { - Observado no anuário do } \\
\text { ensino médio, soma do número de } \\
\text { esportes do time do colégio, esportes } \\
\text { de clube e esportes internos. }\end{array}$ & $\begin{array}{l}\text { Os participantes de famílias } \\
\text { com melhor renda ontexto } \\
\text { detexto de SES em } 1954 \\
\text { apresentaram níveis mais } \\
\text { elevados de atividade física } \\
\text { comparados com os de menor } \\
\text { renda. }\end{array}$ \\
\hline $\begin{array}{l}\text { Torres et } \\
\text { al., } 33\end{array}$ & $\begin{array}{l}\text { Comparar os participantes de } \\
\text { ciclovias e ciclorotas de Bogotá. }\end{array}$ & $\begin{array}{l}2.000 \text { participantes ( } 1.000 \text { de } \\
\text { ciclovias e } 1.000 \text { de ciclorotas). } \\
\text { Maiores de } 18 \text { anos. } \\
\text { Colômbia. }\end{array}$ & IPAQ - Versão longa. & $\begin{array}{l}\text { Os usuários de ciclorrotas } \\
\text { (deslocamento) apresentaram } \\
\text { menor renda. Os usuários de } \\
\text { ciclovias (lazer) apresentaram } \\
\text { maior renda. }\end{array}$ \\
\hline $\begin{array}{l}\text { Lehto et } \\
\text { al., }{ }^{35}\end{array}$ & $\begin{array}{l}\text { Examinar se a auto-eficácia, apoio } \\
\text { social e auto-controle contribuem } \\
\text { para as diferentes situações } \\
\text { socioeconômicas da atividade física } \\
\text { de lazer e atividade física total. }\end{array}$ & $\begin{array}{l}5.024 \text { participantes, sendo } 2.325 \\
\text { homens e } 2.699 \text { mulheres. } \\
\text { Idade de } 25 \text { a } 74 \text { anos. } \\
\text { Finlândia. }\end{array}$ & IPAQ - Versão curta. & $\begin{array}{l}\text { Renda foi associada a níveis } \\
\text { mais elevados de atividade } \\
\text { física no lazer. }\end{array}$ \\
\hline $\begin{array}{l}\text { Kienteka et } \\
\text { al., }{ }^{25}\end{array}$ & $\begin{array}{l}\text { Analisar a associação entre } \\
\text { os aspectos pessoais e } \\
\text { comportamentais no uso de bicicleta } \\
\text { no transporte e no lazer em adultos. }\end{array}$ & $\begin{array}{l}677 \text { participantes. } \\
\text { Idade de } 18 \text { a } 65 \text { anos. } \\
\text { Brasil. }\end{array}$ & IPAQ - Versão longa. & $\begin{array}{l}\text { A atividade física no } \\
\text { deslocamento foi maior em } \\
\text { homens de baixa renda. }\end{array}$ \\
\hline
\end{tabular}


e atividades físicas nos domínios ocupacional e deslocamento em cinco $(23,8 \%)$ estudos ${ }^{11,16,25,27,33}$ indicando que pessoas de menor renda eram mais propensas a apresentar maiores níveis de atividade física nestes domínios.

A escolaridade foi a variável mais comum dentre os estudos analisados nesta revisão, sendo encontrada em $24(55,8 \%)$ dos artigos ${ }^{10,11,14-17,19-22,27-30,32-33,35-40}$. Foram

QUADRO 2 - Características dos estudos que analisaram a associação entre escolaridade e atividade física em adultos e idosos.

\begin{tabular}{|c|c|c|c|c|}
\hline Referência & Objetivo & Amostra/Nação & $\begin{array}{l}\text { Instrumento para medida } \\
\text { de atividade física }\end{array}$ & Resultados \\
\hline $\begin{array}{l}\text { Kahan et } \\
\text { al., }{ }^{9}\end{array}$ & $\begin{array}{l}\text { Avaliar a relação das características } \\
\text { de escolaridade, renda e trabalho, } \\
\text { lazer e esporte com o grau de } \\
\text { atividade física percebida. }\end{array}$ & $\begin{array}{l}445 \text { participantes, sendo } 173 \\
\text { homens e } 211 \text { mulheres. } \\
\text { Idade } 20 \text { a } 65 \text { anos. } \\
\text { Israel. }\end{array}$ & Baecke. & $\begin{array}{l}\text { Baixa escolaridade associada com maior } \\
\text { atividade física no trabalho e menor } \\
\text { atividade física esportiva no lazer. }\end{array}$ \\
\hline $\begin{array}{l}\text { Meyer et } \\
\text { al. }{ }^{27}\end{array}$ & $\begin{array}{l}\text { Analisar a prevalência de atividade } \\
\text { física em participantes com mais } \\
\text { de } 50 \text { anos baseado no perfil } \\
\text { sociodemográfico e variáveis } \\
\text { ambientais. }\end{array}$ & $\begin{array}{l}8.405 \text { participantes, sendo } \\
3.542 \text { homens e } 4.863 \\
\text { mulheres. Maiores de } 50 \\
\text { anos. Residentes da Suíça. }\end{array}$ & $\begin{array}{l}\text { Instrumento construído } \\
\text { especificamente para o } \\
\text { estudo. }\end{array}$ & $\begin{array}{l}\text { A prática regular de atividade física no } \\
\text { lazer, moderada e vigorosa, foi associada } \\
\text { positivamente à escolaridade, em ambos } \\
\text { os sexos. }\end{array}$ \\
\hline He et al.., ${ }^{17}$ & $\begin{array}{l}\text { Examinar as diferenças da } \\
\text { atividade física de lazer, atividade } \\
\text { ocupacional (casa e trabalho) e } \\
\text { atividade física total por raça, etnia } \\
\text { e escolaridade. }\end{array}$ & $\begin{array}{l}9.621 \text { participantes, sendo } \\
4.505 \text { homens e } 5.116 \\
\text { mulheres. } \\
\text { Idíendoe } 5 \text { anos. } \\
\text { Curitiba, uos } \\
\text { 51-61 anos. } \\
\text { Estados Unidos. }\end{array}$ & $\begin{array}{l}\text { Instrumento construído } \\
\text { especificamente para o } \\
\text { estudo. }\end{array}$ & $\begin{array}{l}\text { No sexo masculino o nível de escolaridade } \\
\text { mostrou uma relação muito forte com a } \\
\text { atividade física leve e vigorosa no lazer. } \\
\text { Relação inversa entre escolaridade e } \\
\text { atividade no trabalho. A atividade total foi } \\
\text { igual para os subgrupos de escolaridade. } \\
\text { Nas mulheres foi encontrada uma relação muito } \\
\text { forte com atividade física de lazer leve e vigorosa. }\end{array}$ \\
\hline $\begin{array}{l}\text { Sávio et } \\
\text { al., }{ }^{39}\end{array}$ & $\begin{array}{l}\text { Analisar os fatores } \\
\text { socioeconômicos e demográficos } \\
\text { associados ao nível de atividade } \\
\text { física de trabalhadores. }\end{array}$ & $\begin{array}{l}1.044 \text { trabalhadores } \\
\text { de ambos os sexos } \\
\text { vinculados ao Programa de } \\
\text { Alimentação do Trabalhador. } \\
\text { Idade superior há } 18 \text { anos. } \\
\text { Brasil. }\end{array}$ & $\begin{array}{l}\text { Recordatório de atividades } \\
\text { físicas da semana anterior, } \\
\text { convertido em taxa } \\
\text { metabólica para obtenção } \\
\text { do Nível de Atividade } \\
\text { Física. }\end{array}$ & $\begin{array}{l}\text { Menor escolaridade foi associada com } \\
\text { o maior nível de atividade física de } \\
\text { trabalhadores. }\end{array}$ \\
\hline $\begin{array}{l}\text { Kaleta e } \\
\text { Jegier., }\end{array}$ & $\begin{array}{l}\text { Avaliar a associação entre os } \\
\text { fatores socioeconômicos e } \\
\text { demográficos com a atividade } \\
\text { física de lazer em homens e } \\
\text { mulheres em idade ativa. }\end{array}$ & $\begin{array}{l}954 \text { participantes, sendo } 454 \\
\text { homens e } 502 \text { mulheres. } \\
\text { Idade de } 25 \text { a } 64 \text { anos. } \\
\text { Polônia. }\end{array}$ & $\begin{array}{l}\text { Questionário Country } \\
\text { Wide Noncomunicable } \\
\text { Disease Intervention } \\
\text { Program, World Health } \\
\text { Organization (CINDI, } \\
\text { WHO). }\end{array}$ & $\begin{array}{l}\text { Em ambos os sexos, o nível de escolaridade } \\
\text { foi associado com o nível de atividade no } \\
\text { lazer. Em homens com escolaridade primária, } \\
\text { o nível de inatividade foi três vezes maior } \\
\text { do que homens com nível universitário. } \\
\text { Em mulheres com o primário o risco de } \\
\text { inatividade foi quatro vezes maior do que } \\
\text { em mulheres com escolaridade universitária. }\end{array}$ \\
\hline Lee et al. ${ }^{28}$ & $\begin{array}{l}\text { Descrever os padrões de atividade } \\
\text { física e suas interrelações e } \\
\text { associações com os fatores } \\
\text { socioeconômico individuais } \\
\text { e estilo de vida em homens. } \\
\text { Shangai. }\end{array}$ & $\begin{array}{l}61.582 \text { participantes. Idade } \\
\text { de } 40 \text { a } 74 \text { anos. } \\
\text { China }\end{array}$ & $\begin{array}{l}\text { Instrumento construído } \\
\text { especificamente para o } \\
\text { estudo. }\end{array}$ & $\begin{array}{l}\text { Os níveis de escolaridade foram } \\
\text { positivamente associados ao exercício } \\
\text { no lazer e ao trabalho doméstico, porém } \\
\text { inversamente associado com o transporte } \\
\text { atividades da vida diária. }\end{array}$ \\
\hline $\begin{array}{l}\text { Zaitune et } \\
\text { al., }\end{array}$ & $\begin{array}{l}\text { Conhecer a prevalência de } \\
\text { sedentarismo durante o lazer em } \\
\text { idosos do Município de Campinas } \\
\text { analisando-a segundo fatores } \\
\text { demogr[aficos e socioeconômicos, } \\
\text { presença de comorbidades } \\
\text { e outros comportamentos } \\
\text { relacionados à saúde. }\end{array}$ & $\begin{array}{l}426 \text { idosos com idade igual } \\
\text { ou superior a } 60 \text { anos. } \\
\text { Ambos os sexos. Brasil. }\end{array}$ & $\begin{array}{l}\text { Instrumento construído } \\
\text { especificamente para o } \\
\text { estudo. }\end{array}$ & $\begin{array}{l}\text { Menor escolaridade apresentou associação } \\
\text { significativa com o sedentarismo. }\end{array}$ \\
\hline $\begin{array}{l}\text { Shawe } \\
\text { Spokane. }{ }^{19}\end{array}$ & $\begin{array}{l}\text { Verificar se o nível de escolaridade } \\
\text { está positivamente associado com } \\
\text { a probabilidade de envolvimento } \\
\text { com atividade física e se o } \\
\text { declínio ao longo dos anos está } \\
\text { associado com a escolaridade. }\end{array}$ & $\begin{array}{l}7.595 \text { participantes. } \\
\text { Idade de } 54 \text { a } 72 \text { anos. } \\
\text { Avaliados em } 1.996 \text { e } \\
\text { posteriormente em } 2002 . \\
\text { Estados Unidos da América. }\end{array}$ & $\begin{array}{l}\text { Instrumento construído } \\
\text { especificamente para o } \\
\text { estudo. }\end{array}$ & $\begin{array}{l}\text { Nos menores níveis de escolaridade (a } \\
\text { baixo da média) o emprego foi associado } \\
\text { positivamente com a atividade física. } \\
\text { Nos maiores níveis o emprego foi associado } \\
\text { negativamente com a atividade física. } \\
\text { Aqueles altamente educados estão mais } \\
\text { propensos a praticar atividade física do que } \\
\text { os participantes escolarizados até que a } \\
\text { saúde ou limitações surjam. }\end{array}$ \\
\hline
\end{tabular}


continua

\begin{tabular}{|c|c|c|c|c|}
\hline Referência & Objetivo & Amostra/Nação & $\begin{array}{l}\text { Instrumento para medida } \\
\text { de atividade física }\end{array}$ & Resultados \\
\hline $\begin{array}{l}\text { Kamphuis } \\
\text { et al., }\end{array}$ & $\begin{array}{l}\text { Examinar a contribuição da } \\
\text { vizinhança, casa e fatores de } \\
\text { desigualdades socioeconômicas } \\
\text { na participação em esportes. }\end{array}$ & $\begin{array}{l}3.839 \text { participantes de } 213 \\
\text { bairros. } \\
\text { Idade de } 25 \text { a } 75 \text { anos. } \\
\text { Holanda. }\end{array}$ & $\begin{array}{l}\text { Instrumento construído } \\
\text { especificamente para o } \\
\text { estudo. }\end{array}$ & $\begin{array}{l}\text { As chances de não praticar esporte foram } \\
\text { reduzidas em } 57 \% \text { nos grupos de menor } \\
\text { escolaridade. }\end{array}$ \\
\hline $\begin{array}{l}\text { Siqueira et } \\
\text { al., }^{40}\end{array}$ & $\begin{array}{l}\text { Descrever a prevalência de } \\
\text { sedentarismo e fatores associados } \\
\text { em populações das áreas de } \\
\text { abrangência de unidades básicas } \\
\text { de saúde em municípios das } \\
\text { regiões Sul e Nordeste do Brasil. }\end{array}$ & $\begin{array}{l}4.060 \text { adultos de ambos os } \\
\text { sexos com idade entre } 30 \text { e } \\
64 \text { anos e } 4.003 \text { idosos de } \\
\text { ambos os sexos. Brasil. }\end{array}$ & IPAQ - Versão curta. & $\begin{array}{l}\text { Baixa escolaridade foi associada com o } \\
\text { sedentarismo apenas em idosos. }\end{array}$ \\
\hline Pan et al.,. & $\begin{array}{l}\text { A) analisar se os fatores } \\
\text { individuais, apoio social e } \\
\text { ambiente físico apresentam } \\
\text { efeitos independentes na } \\
\text { atividade física na população } \\
\text { canadense. } \\
\text { B) Verificar se as influências dessas } \\
\text { variáveis sobre a atividade física } \\
\text { variam de acordo com sexo, } \\
\text { idade, escolaridade e nível de } \\
\text { renda familiar. }\end{array}$ & $\begin{array}{l}5.167 \text { participantes sendo } \\
2.313 \text { homens e } 2.854 \\
\text { mulheres. } \\
\text { Idade de } 15 \text { a } 79 \text { anos. } \\
\text { Canadá. }\end{array}$ & IPAQ - Versão curta. & $\begin{array}{l}\text { Conhecimento sobre os benefícios da AF } \\
\text { na saúde e escolaridade tiveram efeito nas } \\
\text { pessoas mais velhas e essa influência foi } \\
\text { mais marcante nas mulheres } \\
\text { O ambiente favorável para prática foi mais } \\
\text { associado com a atividade física entre as } \\
\text { pessoas com um diploma universitário do } \\
\text { que entre as pessoas com um menor nível } \\
\text { de escolaridade. }\end{array}$ \\
\hline $\begin{array}{l}\text { Sjögren et } \\
\text { al.1.14 }\end{array}$ & $\begin{array}{l}\text { Investigar a prática de atividade } \\
\text { física de lazer ao ar livre durante } \\
\text { um ano e os fatores que } \\
\text { influenciam essa atividade em } \\
\text { pessoas com mais de } 60 \text { anos. }\end{array}$ & $\begin{array}{l}999 \text { participantes, sendo } \\
451 \text { homens e } 548 \\
\text { mulheres. } \\
\text { Idade de } 60 \text { a } 94 \text { anos. } \\
\text { Suécia. }\end{array}$ & $\begin{array}{l}\text { Instrumento construído } \\
\text { especificamente para o } \\
\text { estudo. }\end{array}$ & $\begin{array}{l}\text { A prática regular de atividade física no lazer } \\
\text { foi associada positivamente à escolaridade, } \\
\text { em ambos os sexos. }\end{array}$ \\
\hline $\begin{array}{l}\text { Cleland et } \\
\text { al.,.1 }\end{array}$ & $\begin{array}{l}\text { Correlacionar os fatores } \\
\text { individuais, sociais e ambientais } \\
\text { com a atividade física em } \\
\text { uma amostra de mulheres de } \\
\text { um bairro de baixa condição } \\
\text { socioeconômica. }\end{array}$ & $\begin{array}{l}4.108 \text { participantes, Idade } \\
\text { de } 18 \text { a } 45 \text { anos de } 80 \\
\text { bairros ( } 40 \text { bairros rurais e } \\
40 \text { urbanos). } \\
\text { Austrália. }\end{array}$ & IPAQ - Versão longa. & $\begin{array}{l}\text { A prática regular de atividade física no lazer } \\
\text { foi associada positivamente à escolaridade } \\
\text { alta e a atividade de deslocamento foi } \\
\text { associada com a escolaridade baixa. }\end{array}$ \\
\hline $\begin{array}{l}\text { Rovniak et } \\
{\text { al. }{ }^{10}}^{10}\end{array}$ & $\begin{array}{l}\text { Identificar os padrões de atividade } \\
\text { física em diferentes domínios da } \\
\text { vida. }\end{array}$ & $\begin{array}{l}1.689 \text { participantes ( } 2 \\
\text { bairros diferentes). Estados } \\
\text { Unidos. }\end{array}$ & $\begin{array}{l}\text { IPAQ - Versão longa. } \\
\text { Uso de acelerômetro. }\end{array}$ & $\begin{array}{l}\text { A maior pratica ocupacional foi associada a } \\
\text { menor escolaridade. }\end{array}$ \\
\hline $\begin{array}{l}\text { Zanchetta } \\
\text { et al., }{ }^{29}\end{array}$ & $\begin{array}{l}\text { a) analisar as prevalências de } \\
\text { inatividade física global e no lazer, } \\
\text { e a associação desses indicadores } \\
\text { com fatores demográficos e } \\
\text { socioeconômicos em adultos. } \\
\text { b) Avaliar diferenciais nas } \\
\text { modalidades de exercício físico } \\
\text { e esportes praticados segundo a } \\
\text { escolaridade. }\end{array}$ & $\begin{array}{l}2.050 \text { participantes, sendo } \\
1.028 \text { mulheres e } 1.022 \\
\text { homens. } \\
\text { Idade de } 18 \text { a } 59 \text {. } \\
\text { lo, e entre e de } 60 \text {-Brasil. }\end{array}$ & IPAQ - Versão curta. & $\begin{array}{l}\text { A prática regular de atividade física no lazer } \\
\text { foi associada positivamente à escolaridade } \\
\text { em ambos os sexos. }\end{array}$ \\
\hline $\begin{array}{l}\text { Bauman et } \\
\text { al. }{ }^{16}{ }^{16}\end{array}$ & $\begin{array}{l}\text { Descrever como a atividade } \\
\text { física-trabalho, deslocamento } \\
\text { e de lazer - é distribuída por } \\
\text { idade, escolaridade, renda, } \\
\text { área urbana e rural dentro de } \\
\text { cada país e comparar essas } \\
\text { associações entre diferentes } \\
\text { estágios de desenvolvimento } \\
\text { socioeconômico. }\end{array}$ & $\begin{array}{l}\text { Participantes v de lo, entre } \\
18-64 \text { anos. com idade } \\
\text { entre } 18 \text { e } 64 \text { anos. } \\
\text { Austrália } 15.786 \\
\text { (Homens:7.870 / } \\
\text { Mulheres:7.815); } \\
\text { China 142693 } \\
\text { (Homens:6.3931 / } \\
\text { Mulheres: } 78.295) ; \\
\text { Fiji } 6.763 \text { (Homens:2.878 / } \\
\text { Mulhere:3.343); } \\
\text { Malásia 2.572 } \\
\text { (Homens:1.044 / } \\
\text { Mulheres:1.528); } \\
\text { Nauru 2.085 (Homens:925 / } \\
\text { Mulheres:952); } \\
\text { Filipinas 3.307 } \\
\text { (Homens:1.660 / } \\
\text { Mulheres:1.647). }\end{array}$ & $\begin{array}{l}\text { Instrumento construído } \\
\text { especificamente para o } \\
\text { estudo em cada país. }\end{array}$ & $\begin{array}{l}\text { Na China, Fiji e Austrália A prática regular } \\
\text { de atividade física no lazer foi associada } \\
\text { positivamente à escolaridade. } \\
\text { Na China e no Fiji, os homens com alta } \\
\text { escolaridade foi associada a atividade } \\
\text { ocupacional. } \\
\text { Nas Filipinas, Malásia e Nauru a escolaridade } \\
\text { foi negativamente associada com a } \\
\text { atividade de deslocamento. }\end{array}$ \\
\hline
\end{tabular}

Continua.. 
continua

\begin{tabular}{|c|c|c|c|c|}
\hline Referência & Objetivo & Amostra/Nação & $\begin{array}{l}\text { Instrumento para medida } \\
\text { de atividade física }\end{array}$ & Resultados \\
\hline $\begin{array}{l}\text { Nédó e } \\
\text { Paulik., }\end{array}$ & $\begin{array}{l}\text { Estudar as diferenças } \\
\text { socioeconômicos relacionadas } \\
\text { ao comportamento de saúde e } \\
\text { estado nutricional em cidadãos } \\
\text { Húngaros e Romenos. }\end{array}$ & $\begin{array}{l}1.099 \text { húngaros, sendo } 575 \\
\text { mulheres e } 524 \text { homens. } \\
852 \text { romenos, sendo } 437 \\
\text { mulheres e } 415 \text { homens. } \\
\text { Maiores de } 18 \text { anos. } \\
\text { Hungria e Romênia. }\end{array}$ & $\begin{array}{l}\text { Instrumento construído } \\
\text { especificamente para o } \\
\text { estudo em cada país. }\end{array}$ & $\begin{array}{l}\text { A prática regular de atividade física no lazer } \\
\text { não foi associada à escolaridade, em ambos } \\
\text { os sexos. }\end{array}$ \\
\hline $\begin{array}{l}\text { Komar- } \\
\text { Samardzija } \\
\text { et al., }{ }^{20}\end{array}$ & $\begin{array}{l}\text { Determinar a relação da frequência } \\
\text { e do gasto calórico da atividade } \\
\text { física com: } \\
\text { 1)Suporte social. } \\
\text { 2)Auto-eficácia. } \\
\text { 3)Imagem corporal } \\
\text { 4)Barreiras } \\
\text { 5)Escolaridade e renda familiar }\end{array}$ & $\begin{array}{l}50 \text { mulheres afro- } \\
\text { americanas com diabetes } \\
\text { tipo } 2 \text {. } \\
\text { Maiores de } 18 \text { anos. } \\
\text { Estados Unidos da América. }\end{array}$ & $\begin{array}{l}\text { Modifiend CHAMPS } \\
\text { Physical Activity } \\
\text { Questionnaire. }\end{array}$ & $\begin{array}{l}\text { Não foi encontrada associação entre } \\
\text { escolaridade e energia despendida. }\end{array}$ \\
\hline $\begin{array}{l}\text { Pitanga et } \\
\text { al., }{ }^{37}\end{array}$ & $\begin{array}{l}\text { Analisar a prevalência e os fatores } \\
\text { sociodemográficos associados aos } \\
\text { diferentes domínios da atividade } \\
\text { física em adultos de etnia negra. }\end{array}$ & $\begin{array}{l}2.305 \text { adultos com idade } \\
\text { entre } 20 \text { a } 96 \text { anos de } \\
\text { ambos os sexos. }\end{array}$ & IPAQ - Versão longa. & $\begin{array}{l}\text { A maior escolaridade foi associada com } \\
\text { maior atividade física total, ocupacional e } \\
\text { de lazer. }\end{array}$ \\
\hline $\begin{array}{l}\text { Torres et } \\
\text { al., } 33\end{array}$ & $\begin{array}{l}\text { Comparar os participantes de } \\
\text { ciclovias e ciclorotas de Bogotá. }\end{array}$ & $\begin{array}{l}2.000 \text { participantes ( } 1.000 \\
\text { de ciclovias e } 1.000 \text { de } \\
\text { ciclorotas). } \\
\text { Maiores de } 18 \text { anos. } \\
\text { Colômbia. }\end{array}$ & IPAQ - Versão longa. & $\begin{array}{l}\text { Os usuários das ciclorrotas (deslocamento) } \\
\text { apresentam menor escolaridade. } \\
\text { Os usuários das ciclovias (lazer) apresentam } \\
\text { média escolaridade, }\end{array}$ \\
\hline $\begin{array}{l}\text { Lehto et } \\
\text { al., }{ }^{35}\end{array}$ & $\begin{array}{l}\text { Examinar se a auto-eficácia, apoio } \\
\text { social e auto-controle contribuem } \\
\text { para as diferentes situações } \\
\text { socioeconômicas da atividade } \\
\text { física de lazer e atividade física } \\
\text { total. }\end{array}$ & $\begin{array}{l}5.024 \text { participantes, sendo } \\
2.325 \text { homens e } 2.699 \\
\text { mulheres. } \\
\text { Idade de } 25 \text { a } 74 \text { anos. } \\
\text { Finlândia. }\end{array}$ & IPAQ - Versão curta.sa. & $\begin{array}{l}\text { A prática regular de atividade física no lazer } \\
\text { foi associada positivamente à escolaridade, } \\
\text { em ambos os sexos. }\end{array}$ \\
\hline $\begin{array}{l}\text { Federico et } \\
\text { al., }{ }^{31}\end{array}$ & $\begin{array}{l}\text { Avaliar a extensão das diferenças } \\
\text { socioeconômicas na pratica } \\
\text { esportiva e na atividade física em } \\
\text { geral de adultos italianos. }\end{array}$ & $\begin{array}{l}27.760 \text { participantes. Aaico } \\
\text { da Ásia.mbos os sexos. } \\
\text { Idade de } 25 \text { e } 64 \text { anos. } \\
\text { Itália. }\end{array}$ & IPAQ - Versão longa. & $\begin{array}{l}\text { A prática regular de atividade física no lazer } \\
\text { foi associada positivamente à escolaridade, } \\
\text { em ambos os sexos. }\end{array}$ \\
\hline $\begin{array}{l}\text { Kienteka et } \\
\text { al., }{ }^{25}\end{array}$ & $\begin{array}{l}\text { Analisar a associação entre } \\
\text { os aspectos pessoais e } \\
\text { comportamentais no uso de } \\
\text { bicicleta no transporte e no lazer } \\
\text { em adultos. }\end{array}$ & $\begin{array}{l}677 \text { participantes. } \\
\text { Idade de } 18 \text { a } 65 \text { anos. } \\
\text { Brasil. }\end{array}$ & IPAQ - Versão longa. & $\begin{array}{l}\text { A prática regular de atividade física no lazer } \\
\text { e deslocamento não foram associadas à } \\
\text { escolaridade. }\end{array}$ \\
\hline $\begin{array}{l}\text { Freire et } \\
\text { al., }\end{array}$ & $\begin{array}{l}\text { Estimar a prevalência de prática } \\
\text { regular de atividade física e seus } \\
\text { determinantes no município } \\
\text { de Montes Claros, Minas Gerais, } \\
\text { Brasil. }\end{array}$ & $\begin{array}{l}761 \text { adolescentes (15 a 19), } \\
841 \text { adultos ( } 35 \text { a } 44 \text { anos) } \\
\text { e } 740 \text { idosos ( } 64 \text { a } 74 \text { anos). } \\
\text { Ambos os sexos. Brasil. }\end{array}$ & $\begin{array}{l}\text { Instrumento construído } \\
\text { especificamente para o } \\
\text { estudo. }\end{array}$ & $\begin{array}{l}\text { Maior escolaridade foi associada com a } \\
\text { prática de atividade física em adultos e } \\
\text { idosos. }\end{array}$ \\
\hline
\end{tabular}

observados diferentes meios de mensurar a escolaridade: período completo de formação, por exemplo, completar ou não o ensino fundamental ${ }^{25,31,33}$; anos completos de estudo ${ }^{29,35}$, particularmente de forma categórica. Ao analisar a relação da escolaridade com os diferentes domínios da atividade física, foi possível identificar uma associação positiva entre a escolaridade e o domínio do lazer em 16 (66,6\%) estudos $^{10,14,16,17,19,21,22,28,29,30-33,35,37}$, de forma que os participantes de maior escolaridade estavam mais propensos a se engajarem em atividades físicas no lazer. A menor escolaridade foi associada com maior nível de atividade física no domínio ocupacional em sete $(29,1 \%)$ estudos ${ }^{10,11,17,19,21,37,39}$ e associada com maior nível de atividade física no domínio do deslocamento em dois (8,3\%) estudos ${ }^{28,33}$. Assim os participantes de menor escolaridade apresentam maiores níveis de atividades físicas nos domínios ocupacional e deslocamento. Dentre os estudos referentes a prática de atividade física e escolaridade, quatro $(16,6 \%)$ não encontraram associação da escolaridade com os diferentes domínios da atividade física ${ }^{15,20,25,40}$. 
Foram encontrados $10(23,2 \%)$ estudos que evidenciaram em seus resultados alguma medida de referência à condição laboral ${ }^{10,11,16,17,19,21,27,29,30,40}$. Alguns operacionalizaram essa variável como estar ou não empregado ${ }^{19,21,30}$, outros por meio do status da ocupação profissional ${ }^{11,16,29}$. Dois estudos evidenciam que estar empregado é associado com a prática de atividade física no lazer ${ }^{21,40}$, outro fator que demonstrou ser facilitador para a prática de atividade física no lazer foi o status da ocupação profissional, sendo os participantes de pior ocupação aqueles com a menor prática no domínio do lazer ${ }^{10,11,16,17,19,29}$. Dois estudos não verificaram associação entre as práticas de atividades físicas e a variável ocupação ${ }^{27,30}$.

QUADRO 3 - Características dos estudos que analisaram a associação entre trabalho e atividade física em adultos e idosos.

\begin{tabular}{|c|c|c|c|c|}
\hline Referência & Objetivo & Amostra/Nação & $\begin{array}{l}\text { Instrumento para medida } \\
\text { de atividade física }\end{array}$ & Resultados \\
\hline $\begin{array}{l}\text { Kahan et } \\
\text { al., }{ }^{9}\end{array}$ & $\begin{array}{l}\text { Avaliar a relação das características } \\
\text { de escolaridade, renda e trabalho, } \\
\text { lazer e esporte com o grau de } \\
\text { atividade física percebida. }\end{array}$ & $\begin{array}{l}445 \text { participantes, sendo } 173 \\
\text { homens e } 211 \text { mulheres. } \\
\text { Idade } 20 \text { a } 65 \text { anos. } \\
\text { Israel }\end{array}$ & Baecke. & $\begin{array}{l}\text { A prática esportiva foi associada } \\
\text { negativamente a atividade física } \\
\text { ocupacional. }\end{array}$ \\
\hline $\begin{array}{l}\text { Meyer et } \\
\text { al. }{ }^{27}\end{array}$ & $\begin{array}{l}\text { Analisar a prevalência de atividade } \\
\text { física em participantes com mais } \\
\text { de } 50 \text { anos baseado no perfil } \\
\text { sociodemográfico e variáveis } \\
\text { ambientais. }\end{array}$ & $\begin{array}{l}8.405 \text { participantes, sendo } 3.542 \\
\text { homens e } 4.863 \text { mulheres. } \\
\text { Maiores de } 50 \text { anos. Residentes } \\
\text { da Suiça. }\end{array}$ & $\begin{array}{l}\text { Instrumento construído } \\
\text { especificamente para o } \\
\text { estudo. }\end{array}$ & $\begin{array}{l}\text { A prática regular de atividade física no } \\
\text { lazer não foi associada ao trabalho em } \\
\text { ambos os sexos. }\end{array}$ \\
\hline He et al.,. ${ }^{17}$ & $\begin{array}{l}\text { Examinar as diferenças da } \\
\text { atividade física de lazer, atividade } \\
\text { ocupacional (casa e trabalho) } \\
\text { eatividade física total por raça, } \\
\text { etnia e escolaridade. }\end{array}$ & $\begin{array}{l}9.621 \text { participantes, sendo } 4.505 \\
\text { homens e } 5.116 \text { mulheres. } \\
\text { Idíendoe } 5 \text { anos. } \\
\text { Curitiba, uos } \\
51-61 \text { anos. } \\
\text { Estados Unidos. }\end{array}$ & $\begin{array}{l}\text { Instrumento construído } \\
\text { especificamene para o } \\
\text { estudo. }\end{array}$ & $\begin{array}{l}31 \% \text { da amostra relata trabalho } \\
\text { extenuante. } \\
\text { Mulheres relatam menor frequência de } \\
\text { atividade ocupacional, porém vigoroso } \\
\text { igual aos homens. } \\
\text { Mulheres negras estão mais propensas à } \\
\text { atividade de trabalho do que mulheres } \\
\text { brancas, assim como os homens negros e } \\
\text { hispânicos em relação aos homens brancos. }\end{array}$ \\
\hline $\begin{array}{l}\text { Kaleta e } \\
\text { Jegier., }\end{array}$ & $\begin{array}{l}\text { Avaliar a associação entre os } \\
\text { fatores socioeconomicos e } \\
\text { demográficos com a atividade } \\
\text { física de lazer em homens e } \\
\text { mulheres em idade ativa. }\end{array}$ & $\begin{array}{l}954 \text { participantes, sendo } 454 \\
\text { homens e } 502 \text { mulheres. } \\
\text { Idade de } 25 \text { a } 64 \text { anos. } \\
\text { Polônia }\end{array}$ & $\begin{array}{l}\text { Questionário Country Wide } \\
\text { Noncomunicable Disease } \\
\text { Intervention Program, } \\
\text { World Health Organization } \\
\text { (CINDI, WHO). }\end{array}$ & $\begin{array}{l}\text { A prática regular de atividade física no } \\
\text { lazer não foi associada ao trabalho em } \\
\text { ambos os sexos. }\end{array}$ \\
\hline $\begin{array}{l}\text { Shaw e } \\
\text { Spokane., }{ }^{19}\end{array}$ & $\begin{array}{l}\text { a) Analisar se a atividade física } \\
\text { diminui com a idade. } \\
\text { b) Verificar se o nível de } \\
\text { escolaridade está positivamente } \\
\text { associado com a probabilidade } \\
\text { de envolvimento com atividade } \\
\text { física e se o declínio ao longo } \\
\text { dos anos está associado com a } \\
\text { escolaridade. } \\
\text { c) Verificar se o aumento da } \\
\text { idade, dos problemas de saúde } \\
\text { e participação no trabalho está } \\
\text { associado com menores taxas de } \\
\text { atividade física posteriormente } \\
\text { e se essa relação é maior em } \\
\text { participantes de níveis baixos de } \\
\text { escolaridade. }\end{array}$ & $\begin{array}{l}\text { Total de } 7.595 \text { com idade entre } \\
54 \text { e } 72 \text { anos. } \\
\text { Participantes avaliados em } \\
1996 \text { e posteriormente em } \\
\text { 2002. } \\
\text { Estados Unidos da América. }\end{array}$ & $\begin{array}{l}\text { Instrumento construído } \\
\text { especificamente para o } \\
\text { estudo. }\end{array}$ & $\begin{array}{l}\text { A atividade física foi mais comum } \\
\text { em trabalhadores do que em não } \\
\text { trabalhadores. } \\
\text { A atividade física foi associada } \\
\text { positivamente com menor nível do } \\
\text { emprego. }\end{array}$ \\
\hline $\begin{array}{l}\text { Siqueira et } \\
\text { al. }{ }^{40}\end{array}$ & $\begin{array}{l}\text { Descrever a prevalência de } \\
\text { sedentarismo e fatores associados } \\
\text { em populações das áreas de } \\
\text { abrangência de unidades básicas } \\
\text { de saúde em municípios das } \\
\text { regiões Sul e Nordeste do Brasil. }\end{array}$ & $\begin{array}{l}4.060 \text { adultos de ambos os } \\
\text { sexos com idade entre } 30 \text { e } 64 \\
\text { anos e } 4.003 \text { idosos de ambos } \\
\text { os sexos. Brasil. }\end{array}$ & IPAQ - Versão curta. & $\begin{array}{l}\text { O trabalho remunerado foi fator de } \\
\text { proteção para o sedentarismo em idosos }\end{array}$ \\
\hline
\end{tabular}


. continua

\begin{tabular}{|c|c|c|c|c|}
\hline Referência & Objetivo & Amostra/Nação & $\begin{array}{l}\text { Instrumento para medida } \\
\text { de atividade física }\end{array}$ & Resultados \\
\hline $\begin{array}{l}\text { Cleland et } \\
\text { al.., }{ }^{21}\end{array}$ & $\begin{array}{l}\text { Correlacionar os fatores } \\
\text { individuais, sociais e ambientais } \\
\text { com a atividade física em } \\
\text { uma amostra de mulheres de } \\
\text { um bairro de baixa condição } \\
\text { socioeconômica. }\end{array}$ & $\begin{array}{l}4.108 \text { participantes do sexo } \\
\text { feminino } \\
\text { Idade de } 18 \text { a } 45 \text { anos de } 80 \\
\text { bairros ( } 40 \text { rural e } 40 \text { urbanos). } \\
\text { Austrália. }\end{array}$ & IPAQ - Versão longa. & $\begin{array}{l}\text { A atividade física no lazer foi associada } \\
\text { positivamente com estar empregada } \\
\text { em tempo integral, enquanto a } \\
\text { atividade de deslocamento foi associada } \\
\text { positivamente com estar desempregada. }\end{array}$ \\
\hline $\begin{array}{l}\text { Rovniak et } \\
\text { al., }{ }^{10}\end{array}$ & $\begin{array}{l}\text { Identificar os padrões de } \\
\text { atividade física em diferentes } \\
\text { domínios da vida. }\end{array}$ & $\begin{array}{l}1689 \text { participantes ( } 2 \text { bairros } \\
\text { diferentes). Estados Unidos }\end{array}$ & IPAQ - Versão longa. & $\begin{array}{l}\text { O grupo de maior atividade ocupacional } \\
\text { é mais propenso a ser do sexo } \\
\text { masculino, menor renda e escolaridade e } \\
\text { viver em um bairro mais pobre. }\end{array}$ \\
\hline $\begin{array}{l}\text { Zanchetta } \\
\text { et al., }\end{array}$ & $\begin{array}{l}\text { a) analisar as prevalências de } \\
\text { inatividade física global e no lazer, } \\
\text { e a associação desses indicadores } \\
\text { com fatores demográficos e } \\
\text { socioeconômicos em adultos. } \\
\text { b) Avaliar diferenciais nas } \\
\text { modalidades de exercício físico } \\
\text { e esportes praticados segundo a } \\
\text { escolaridade. }\end{array}$ & $\begin{array}{l}2.050 \text { participantes, sendo } \\
1.028 \text { mulheres e } 1.022 \\
\text { homens. } \\
\text { Idade entre } 18 \text { e } 59 \text {. } \\
\text { Brasil. }\end{array}$ & IPAQ - Versão curta. & $\begin{array}{l}\text { Homens inativos no lazer apresentaram } \\
\text { uma ocupação de menor qualificação, } \\
\text { enquanto os de maior qualificação são } \\
\text { inativos na atividade física total. } \\
\text { Mulheres inativas no lazer apresentam } \\
\text { menor qualificação ocupacional, } \\
\text { desempregadas e do lar. Na atividade } \\
\text { física total as mais inativas apresentaram } \\
\text { as menores qualificações. }\end{array}$ \\
\hline $\begin{array}{l}\text { Bauman et } \\
\text { al., }{ }^{16}\end{array}$ & $\begin{array}{l}\text { Descrever como a atividade } \\
\text { física-trabalho, deslocamento } \\
\text { e de lazer - é distribuída por } \\
\text { idade, escolaridade, renda, } \\
\text { área urbana e rural dentro de } \\
\text { cada país e comparar essas } \\
\text { associações entre diferentes } \\
\text { estágios de desenvolvimento } \\
\text { socioeconômico }\end{array}$ & $\begin{array}{l}18 \text { a } 64 \text { anos. } \\
\text { Austrália } 15.786 \text { (H:7.870 / } \\
\text { M:7.815); } \\
\text { China 142.693 (H:63.931 / M: } \\
\text { 78.295); } \\
\text { Fiji } 6.763 \text { (H:2.878 / M:3.343); } \\
\text { Malásia 2.572 (H:1.044 / } \\
\text { M:1.528); } \\
\text { Nauru 2.085 (H:925 / M:952); } \\
\text { Filipinas 3.307 (H:1.660 / } \\
\text { M:1.647). }\end{array}$ & $\begin{array}{l}\text { Instrumento construído } \\
\text { especificamente para o } \\
\text { estudo em cada país. }\end{array}$ & $\begin{array}{l}\text { A atividade ocupacional foi associada } \\
\text { positivamente com maior renda e } \\
\text { escolaridade e negativamente associada } \\
\text { com a idade. } \\
\text { A população rural é mais propensa a } \\
\text { atividade física ocupacional. }\end{array}$ \\
\hline
\end{tabular}

\section{Discussão}

Foi possível observar, nesta revisão, que a atividade física está associada aos fatores socioeconômicos, sobretudo a renda, trabalho e escolaridade. De tal modo que os participantes de menor escolaridade, menor renda e/ou pior qualificação profissional estão sujeitos aos maiores níveis de atividade física nos domínios do deslocamento e/ou ocupacional. Por outro lado, o grupo social de maior renda, maior escolaridade e com melhor status profissional estão mais propensos a se engajarem em atividades físicas no lazer.

As associações entre prática de atividade física e renda podem estar determinadas pela forma de análise das pesquisas, por exemplo, ao se avaliar a atividade física global, sem isolar cada domínio, a menor renda pode estar associada com a maior prática de atividade física por estes participantes apresentarem um maior nível de atividade física ocupacional ${ }^{29}$. Portanto é importante que a análise aconteça de acordo com cada domínio da atividade física, visto que tal associação se comporta diferente de acordo com o domínio da atividade observada, seja no lazer, deslocamento ou ocupacional.

É importante observar que por um lado, os participantes de alta renda estão privilegiados para realizarem atividades físicas no lazer, por outro, os de menor renda parecem estar mais vulneráveis à maior nível de atividade física ocupacional $^{10,11,25}$ e de deslocamento ${ }^{25,33}$. Na China, homens e mulheres de alta renda estavam menos propensos a serem fisicamente ativos no trabalho e no deslocamento $^{16}$. Lee et al., ${ }^{28}$ observaram que a renda é positivamente associada ao exercício e ao trabalho doméstico, porém inversamente associado com a atividade física de deslocamento. 
Foi possível observar nesta revisão que a renda também se relaciona com a intensidade da prática de atividade física. Cruz et al., ${ }^{26}$ identificaram que participantes de baixa renda praticam atividades leves, enquanto aqueles de maior renda apresentaram maior participação em atividade física de intensidade moderada, embora sem significância estatística. Estes achados merecem análises mais complexas, de forma que os futuros estudos diferenciem os domínios da atividade física, visto que os diferentes domínios da prática de atividade física podem estar orientados também pela renda e podem apresentar desfechos diferentes para a saúde.

Kamphuis et al., ${ }^{32}$ evidenciam que as chances de não praticar esporte estão reduzidas em $57 \%$ nos grupos de menor escolaridade. Assim como a renda, a escolaridade é associada de forma diferente com cada domínio da atividade física. A baixa escolaridade está associada com maior atividade física no trabalho e a uma menor atividade física esportiva ${ }^{10}$. No estudo de He et al., ${ }^{17}$, o nível de escolaridade mostrou uma relação muito forte com a atividade física de lazer leve e vigorosa e uma relação inversa entre a escolaridade e a atividade física no trabalho. Porém, ao analisar a atividade física total relacionada à escolaridade, não foi verificada associação. Isso reforça a importância de se realizar uma análise para os diferentes domínios da atividade física.

Segundo Bauman et al., ${ }^{16}$ na China, Fiji e Austrália os participantes com alta escolaridade foram mais propensos para atividade física de lazer em comparação com aqueles com menor escolaridade. Na China e no Fiji, os homens com alta escolaridade eram menos propensos a se envolverem em atividades físicas no trabalho em comparação com os de menor escolaridade. Homens e mulheres com maior escolaridade foram menos propensos a se envolver em deslocamento ativo. Não houve associações entre escolaridade e atividade física na Filipinas, Malásia e Nauru.

O nível de escolaridade ainda pode ter impacto diferente sobre cada sexo. Em homens com educação primária, o nível de inatividade é três vezes maior do que naqueles de nível universitário ${ }^{30}$. Em mulheres com apenas o nível primário, a possibilidade de inatividade chega a ser quatro vezes maior do que em mulheres com escolaridade universitária ${ }^{30}$.

A atividade física total é maior em trabalhadores do que em não trabalhadores ${ }^{19}$. Esta associação entre a prática de atividade física estar ou não empregada foi investigada também por Cleland et al., ${ }^{21}$ o qual evidenciaram que mulheres empregadas em tempo integral estão mais engajadas em atividade física no lazer, por outro lado, mulheres desempregadas apresentam maior atividade física de deslocamento.

A prática de atividade física ocupacional parece ter impacto diferenciado em subgrupos, especialmente naqueles historicamente vulneráveis. Mulheres apresentam menor frequência de atividade física do que homens, porém de maior intensidade ${ }^{17}$. Mulheres negras estavam mais propensas à atividade no trabalho do que mulheres brancas, assim como os homens negros e hispânicos em relação aos homens brancos dos Estados Unidos da América ${ }^{17}$.

Uma forma importante de avaliar a atividade física ocupacional diz respeito à análise a partir da qualificação da ocupação. Segundo Zancheta et al., ${ }^{29}$, participantes de maior qualificação profissional foram mais ativos no lazer quando comparados aos participantes de menor qualificação. Shaw e Spokane ${ }^{19}$ reforçam que a relação da atividade física e o emprego podem ainda sofrer influência da escolaridade. Dessa forma, o emprego é associado positivamente com a atividade física apenas nos níveis mais baixos de escolaridade, associação negativa entre trabalho e atividade física seria observada nos maiores níveis de escolaridade.

Nesta revisão foi possível observar que a prática de atividade física está associada aos fatores renda, trabalho e escolaridade. A análise da atividade física em seus 
diferentes domínios, a partir destas variáveis, permitiu a identificação de grupos vulneráveis. Participantes de menor escolaridade, menor renda, com pior qualificação profissional ou desempregados estão sujeitos a uma prática insuficiente de atividade física no lazer e, por outro lado, a uma maior sobrecarga física de deslocamento e ocupacional.

Além da renda, escolaridade e trabalho, outras variáveis encontradas nesta revisão apontam que a prática de atividade física parece estar associada a fatores sociais de contexto mais amplo do que os analisados a partir de características individuais dos participantes. Sendo as variáveis como, viver em um ambiente com características favoráveis à prática de atividade física no lazer, como por exemplo, maior sensação de segurança e acesso a áreas para caminhar, estão associadas a uma maior probabilidade de participação nas atividades físicas no lazer ${ }^{12,21,44}$. Por outro lado, residir em áreas de maior precariedade social está associado a uma menor chance de praticar atividade física no lazer ${ }^{21,23}$.

Outras variáveis poderiam ampliar ainda mais a investigação e o debate, como o produto interno bruto (PIB), caso envolvesse a comparação entre países, questões de gênero, aspectos geográficos e climáticos, a maior urbanização, entre outras. Contudo, é preciso compreender que estas variáveis não estão dissociadas de um contexto social mais amplo, e sobretudo é preciso pensar o que estaria contribuindo para estes determinantes da prática de atividade física. Acredita-se que os resultados do presente estudo demonstram que não é admissível, de forma simplória, culpar o sujeito por não se engajar regularmente em programas de atividades físicas no lazer, na medida em que, ao mesmo tempo, pesa sobre si aspectos que o tornam (e a coletividade que o cerca) mais vulnerável.

É necessário pensar em uma política de promoção da atividade física para estes grupos vulneráveis, porém, esta política precisa ser desenhada em um contexto de promoção de acesso a serviços, espaços públicos adequados e diminuição das desigualdades sociais. O contrário disto, uma promoção com foco individual, estaria sobrecarregando os participantes já submetidos a um maior nível de atividade ocupacional e deslocamento inadequado.

Conclui-se que os estudos sobre condição socioeconômica e a prática de atividade física investigaram, em sua maior parte, as variáveis renda, escolaridade e trabalho. O maior nível de atividade física no lazer em grande parte dos estudos está associada com uma maior renda, maior escolaridade e status profissional. Enquanto o maior nível de atividade física ocupacional e/ou deslocamento foi associada com a menor renda, menor escolaridade e pior status profissional. Recomenda-se que estudos posteriores abranjam temas referentes a fatores coletivos, como desigualdade social, IDH, violência, entre outros fatores e que estas análises aconteçam nos diferentes domínios da atividade física.

\section{Contribuição dos autores}

P. A. F. Rodrigues (0000-0003-3722-4385) e A. Palma (0000-0002-4679-9191) conceberam o estudo, realizaram a busca, escreveram o manuscrito e a redação final. M. P. Melo (0000-0002-0146-4275) e M. R. Assis (0000-0002-2747-2601) realizaram a revisão crítica e participaram da redação final. Todos os autores aprovaram a versão final a ser publicada.

\section{Conflito de interesses}

Os autores do manuscrito declaram a inexistência de conflito de interesses. 


\section{Referências}

1. Garber CE, Blissmer B, Deschenes MR, Franklin BA, Lamonte MJ, Lee IM, et al. American College of Sports Medicine position stand. Quantity and quality of exercise for developing and maintaining cardiorespiratory, musculoskeletal, and neuromotor fitness in apparently healthy adults: guidance for prescribing exercise. Med Sci Sports Exerc. 2011;43(7):1334-59.

2. Lima DF, Levy RB, Luiz OD. Recomendações para atividade física e saúde: consensos, controvérsias e ambiguidades. Rev Panam Salud Pública. 2014;36(3):164-70.

3. Palma A. Exercício físico e saúde: sedentarismo e doença: epidemia, causalidade e moralidade. Motriz Rev Educ Fís. 2009;15(1):185-91.

4. Bagrichevsky M, Castiel LD, Vasconcellos-Silva PR, Estevão A. Discursos sobre comportamento de risco à saúde e a moralização da vida cotidiana. Ciênc Saúde Coletiva. 2010;15(Sup11):1699-08.

5. Ferreira MS, Castiel LD, Cardoso MH. A patologização do sedentarismo. Saúde Soc. 2012;21(4):836-47.

6. Ferreira, MS. Agite antes de usar. A promoção da saúde em programas brasileiros de promoção da atividade física: o caso do agita. (Tese de Doutorado). Rio de Janeiro: Escola Nacional de Saúde Pública Sérgio Arouca, Fundação Oswaldo Cruz; 2008

7. Matsudo S, Matsudo V, Araujo T, Andrade D, Oliveira L, Santos M, et al. Do diagnóstico à ação: a experiência do Programa Agita São Paulo na promoção do estilo de vida ativo. Rev Bras Ativ Fís Saúde. 2012;13(3):178-84.

8. Fraga AB. Exercício da informação: governo dos corpos no mercado da vida ativa. 1. ed. São Paulo: Autores Associados; 2006.

9. Galobardes B, Shaw M, Lawlor DA, Lynch JW. Indicators of socioeconomic position (part1). J Epidemiol Community Healt. 2006;60(1):7-12.

10. Kahan E, Fogelman Y, Bloch B. Correlations of work, leisure, and sports physical activities and health status with socioeconomic factors: a national study in Israel. Postgrad Med J. 2005;81(954):262-65.

11. Rovniak LS, Sallis JF, Saelens BE, Frank LD, Marshall SJ, Norman GJ, et al. Adults' physical activity patterns across life domains: cluster analysis with replication. Health Psychol. 2010;29(5):496-05.

12. Sundquist K, Eriksson U, Kawakami N, Skog L, Ohlsson H, Arvidsson D. Neigh borhood walkability, physical activity, and walking behavior: the Swedish Neighborhood and Physical Activity (SNAP) study. Soc Sci Med. 2011;72(8):1266-73.

13. Giles-Corti B, Donovan RJ. Relative influences of individual, social environmental, and physical environmental correlates of walking. Am J public Health. 2003;93(9):1583-89.

14. Sjogren K, Stjernberg L. A gender perspective on factors that influence outdoor recreational physical activity among the elderly. BMC Geriatr. 2010;10(34):1-9.

15. Nédó E, Paulik E. Association of smoking, physical activity, and dietary habits with socioeconomic variables: a cross-sectional study in adults on both sides of the HungarianRomanian border. BMC Public Health. 2012;12(1):1-10.

16. Bauman A, Ma G, Cuevas F, Omar Z, Waqanivalu T, Phongsavan P, et al. Crossnational comparisons of socioeconomic differences in the prevalence of leisure-time and occupational physical activity, and active commuting in six Asia-Pacific countries. J Epidemiol Community Health. 2011;65(1):35-3.

17. He XZ, Baker DW. Differences in leisure-time, household, and work-related physical activity by race, ethnicity, and education. J Gen Intern Med. 2005;20(3):259-66.

18. Pudrovska T, Anishkin A. Early-Life Socioeconomic Status and Physical Activity in Later Life Evidence From Structural Equation Models. J Aging health. 2013;25(3):383-04.

19. Shaw BA, Spokane LS. Examining the association between education level and physical activity changes during early old age. J Aging Health. 2008;20(7):767-87.

20. Komar-Samardzija M, Braun LT, Keithley JK, Quinn LT. Factors associated with physical activity levels in African-American women with type 2 diabetes. J Am Acad Nurse Pract. 2012;24(4):209-17.

21. Cleland V, Ball K, Hume C, Timperio A, King AC, Crawford D. Individual, social and environmental correlates of physical activity among women living in socioeconomically disadvantaged neighbourhoods. Soc Sci Med. 2010;70(12):2011-18. 
22. Pan SY, Cameron C, DesMeules M, Morrison H, Craig CL, Jiang X. Individual, social, environmental, and physical environmental correlates with physical activity among Canadians: a cross-sectional study. BMC Public Health. 2009;9(1):9-21.

23. Boone-Heinonen J, Roux AV, Kiefe CI, Lewis CE, Guilkey DK, Gordon-Larsen, P. Neighborhood socioeconomic status predictors of physical activity through young to middle adulthood: the CARDIA study. Soc Sci Med. 2011;72(5):641-49.

24. Sundquist K, Eriksson U, Kawakami N, Skog L, Ohlsson H, Arvidsson D. Neighborhood walkability, physical activity, and walking behavior: the Swedish Neighborhood and Physical Activity (SNAP) study. Soc Sci Med. 2011;72(8):1266-73.

25. Kienteka M, Reis RS, Rech CR. Personal and behavioral factors associated with bicycling in adults from Curitiba, Parana State, Brazil. Cad Saúde Pública. 2014;30(1):79-7.

26. Cruz SY, Fabián C, Pagán I, Ríos JL, González AM, Betancourt J, et al. Physical activity and its associations with sociodemographic characteristics, dietary patterns, and perceived academic stress in students attending college in Puerto Rico. P R Health Sci J. 2013;32(1):44-50.

27. Meyer K, Rezny L, Breuer C, Lamprecht M, Stamm HP. Physical activity of adults aged 50 years and older in Switzerland. Soz Praventivmed. 2005;50(4):218-29.

28. Lee SA, Xu WH, Zheng W, Li H, Yang G, Xiang YB, et al. Physical activity patterns and their correlates among Chinese men in Shanghai. Med Sci Sports Exerc. 2007;39(10):1700-07.

29. Zanchetta LM, Barros MB, César CL, Carandina L, Goldbaum M, Alves MC. Inatividade física e fatores associados em adultos, São Paulo, Brasil. Rev Bras Epidemiol. 2010;13(3):387-99.

30. Kaleta D, Jegier A. Predictors of inactivity in the working-age population. Int J Occup Med Environ Health. 2007;20(2):175-82.

31. Federico B, Falese L, Marandola D, Capelli G. Socioeconomic differences in sport and physical activity among Italian adults. J Sports Sci. 2013;31(4):451-58.

32. Kamphuis CB, Van LentheFJ, Giskes K, Huisman M,BrugJ,Mackenbach,JP.Socioeconomic status, environmental and individual factors, and sports participation. Med Sci Sports Exerc. 2008;40(1):71-1.

33. Torres A, Sarmiento OL, Stauber C, Zarama R. The Ciclovia and Cicloruta programs: promising interventions to promote physical activity and social capital in Bogotá, Colombia. Am J Public Health. 2013;103(2):e23-e30.

34. Trinh OT, Nguyen ND, Dibley MJ, Phongsavan P, Bauman AE. The prevalence and correlates of physical inactivity among adults in Ho Chi Minh City. BMC Public Health. 2008;8:204-15.

35. Lehto E, Konttinen H, Jousilahti P, Haukkala, A. The role of psychosocial factors in socioeconomic differences in physical activity: a population-based study. Scand J Public Health. 2013;41(6):553-59.

36. Freire RS, Lélis, FLDO, Fonseca Filho JAD, Nepomuceno MO, Silveira MF. Prática regular de atividade física: estudo de base populacional no Norte de Minas Gerais, Brasil. Ver Bras Med Esporte. 2014;20(5):345-49.

37. Pitanga, FJG, Lessa I, Barbosa PJB, Barbosa, SJO, Costa, MC, Lopes ADS. Fatores sociodemográficos associados aos diferentes domínios da atividade física em adultos de etnia negra. Rev Bras Epidemiol. 2012;15(2):363-75.

38. Zaitune AMP, de Azevedo Barros, MB, César CLG, Carandina L, Goldbaum M. Fatores associados ao sedentarismo no lazer em idosos, Campinas, São Paulo, Brasil. Cad Saúde Pública. 2007;23(6):1329-38.

39. Sávio KEO, da Costa THM, Schmitz BDAS, da Silva EF. Sexo, renda e escolaridade associados ao nível de atividade física de trabalhadores. Rev Saúde Públ. 2008;42(3):457-63.

40. Siqueira FV, Facchini LA, Piccini RX, Tomasi E, Thumé E, Silveira DSD, Hallal P. Atividade física em adultos e idosos residentes em áreas de abrangência de unidades básicas de saúde de municípios das regiões Sul e Nordeste do Brasil. Cad saúde pública. 2008;24(1):39-54.

41. Molina-García J, Sallis J, Castillo I. Active commuting and sociodemographic factors among university students in Spain. J Phys Act Health. 2014;11(2):359-63.

42. Williams ED, Stamatakis E, Chandola T, Hamer M. Assessment of physical activity levels in South Asians in the UK: findings from the Health Survey for England. J Epidemiol Community Health. 2011;65(6):517-21. 
43. Lee RE, Cubbin C, Winkleby M. Contribution of neighbourhood socioeconomic status and physical activity resources to physical activity among women. J Epidemiol Community Health. 2007;61(10):882-90.

44. Tucker-Seeley RD, SubramanianSV,LiY, Sorensen G. Neighborhood safety, socioeconomic status, and physical activity in older adults. Am J Prev Med. 2009;37(3):207-13.

45. Jurj AL, Wen W, Gao YT, Matthews CE, Yang G, Li HL, Shu XO. Patterns and correlates of physical activity: a cross-sectional study in urban Chinese women. BMC public health. 2007;7(1):213.

46. Florindo AA, Salvador EP, Reis RS, Guimarães VV. Perception of the environment and practice of physical activity by adults in a low socioeconomic area. Ver Saude Publica. 2011;45(2):302-10.

47. Hallal PC, Matsudo SM, Matsudo VK, Araújo TL, Andrade DR, Bertoldi AD. Physical activity in adults from two Brazilian areas: similarities and differences. Cad Saúde Pública. 2005;21(2):573-80.

48. Michael YL, Perdue LA, Orwoll ES, Stefanick ML, Marshall LM. Physical activity resources and changes in walking in a cohort of older men. Am J Public Health. 2010;100(4):654-60.

49. Medina C, Janssen I, Campos I, Barquera S. Physical inactivity prevalence and trends among Mexican adults: results from the National Health and Nutrition Survey (ENSANUT) 2006 and 2012. BMC Public Health. 2013;13(1):1063.

50. Reis HFCD, Ladeia AMT, Passos EC, Santos FGDO, Wasconcellos LTD, Correia LCL, Rocha MDS. Prevalence and variables associated with physical inactivity in individuals with high and low socioeconomic status. Arq Bras Cardiol. 2009;92(3):203-8.

51. Keegan TH, Hurley S, Goldberg D, Nelson DO, Reynolds P, Bernstein L, Gomez SL, et al. The association between neighborhood characteristics and body size and physical activity in the California teachers study cohort. Am J Public Health. 2012;102(4):689-97.

52. Chen YJ, Huang YH, Lu FH, Wu JS, Lin LL, Chang CJ, Yang YC. The correlates of leisure time physical activity among an adults population from southern Taiwan. BMC Public Health. 2011;11(1);427.

53. Bosdriesz JR, Witvliet MI, Visscher TL, Kunst AE. The influence of the macro-environment on physical activity: a multilevel analysis of 38 countries worldwide. Int J Behav Nutr Phys Act. 2012;9(1):110.

54. Kavanagh AM, Goller JL, King T, Jolley D, Crawford D, Turrell G. Urban area disadvantage and physical activity: a multilevel study in Melbourne, Australia. J Epidemiol Community Health. 2005;59(11):934-40.

55. Roohafza H, Sadeghi M, Shirani S, Bahonar A, Mackie M, Sarafzadegan N. Association of socioeconomic status and life-style factors with coping strategies in Isfahan Healthy Heart Program, Iran. Croat Med J. 2009;50(4):380-86.

56. Guessous I, Gaspoz JM, Theler JM, Kayser B. Eleven-year physical activity trends in a Swiss urban area. Prev Med. 2014;59:25-30.

57. Bell S, Lee C. Emerging adulthood and patterns of physical activity among young Australian women. Int J Behav Med. 2005;12(4):227-35.

58. Gomes TNQF, dos Santos FK, Garganta RM, Kenny DA, Katzmarzyk PT, Maia JAR. Multilevel modelling of physical activity in nuclear families. Ann Hun Biol. 2014;41(2):138-44.

59. Lee RE, Mama SK, McAlexander KP, Adamus H, Medina AV. Neighborhood and PA: neighborhood factors and physical activity in African American public housing residents. J Phys Act Health. 2011;8(s1):S83-S90.

60. Sjögren K, Hansson EE, Stjernberg L. Parenthood and factors that influence outdoor recreational physical activity from a gender perspective. BMC Public Health. 2011;11(1):93.

61. Kamphuis CB, van Lenthe FJ, Giskes K, Brug J, Mackenbach JP. Perceived environmental determinants of physical activity and fruit and vegetable consumption among high and low socioeconomic groups in the Netherlands. Health Place. 2007;13(2):493-503.

62. Badland H, Schofield G. Perceptions of replacing car journeys with non-motorized travel: Exploring relationships in a cross-sectional adult population sample. Prev Med. 2006;43(3):222-25.

63. McAlexander KM, Banda JA, McAlexanderJW, Lee RE. Physical activity resource attributes and obesity in low-income African Americans. J Urban Health. 2009;86(5):696-707. 
64. Naseer M, Khoso A, Naqvi S, Irfan H. Sex-based difference in the perception of exercise and level of physical activity among residents of Karachi City, Pakistan. J Phys Act Health. 2013;10(7):1039-47.

65. Riva M, Gauvin L, Richard L. Use of local area facilities for involvement in physical activity in Canada: insights for developing environmental and policy interventions. Health Promot Int. 2007;22(3):227-35.

66. Kaplan, GA, Keil JE. Socioeconomic factors and cardiovascular disease: a review of the literature. Circulation. 1993;88(4):1973-98.

Endereço para

Correspondência

Phillipe Augusto Ferreira Rodrigues

rodriguespaf2@gmail.com
Rua Cardoso de Moraes, 350, apt 301,

Bonsucesso, Rio de Janeiro, RJ

CEP: 21032000

Telefone: (21) 99291-0090
Recebido

Revisado

$07 / 11 / 2016$

Aprovado $01 / 04 / 2017$ 